Chapman University

Chapman University Digital Commons

Sociology Faculty Articles and Research

Sociology

$7-2013$

\title{
Cardiovascular Health: Associations with Race- ethnicity, Nativity, and Education in a Diverse, Population-based Sample of Californians
}

Georgiana Bostean

Chapman University, gbostean@chapman.edu

Christian K. Roberts

University of California - Los Angeles

Catherine M. Crespi

University of California - Los Angeles

Michael Prelip

University of California - Los Angeles

Anne Peters

University of Southern California

See next page for additional authors

Follow this and additional works at: http://digitalcommons.chapman.edu/sociology_articles

Part of the Cardiology Commons, Educational Sociology Commons, Medicine and Health Commons, and the Race and Ethnicity Commons

\section{Recommended Citation}

Bostean, Georgiana, et al. 2013. "Cardiovascular health: associations with race-ethnicity, nativity, and education in a diverse, population-based sample of Californians." Annals of Epidemiology 23(7): 388-394. doi:10.1016/j.annepidem.2013.04.012

This Article is brought to you for free and open access by the Sociology at Chapman University Digital Commons. It has been accepted for inclusion in Sociology Faculty Articles and Research by an authorized administrator of Chapman University Digital Commons. For more information, please 


\section{Cardiovascular Health: Associations with Race-ethnicity, Nativity, and Education in a Diverse, Population-based Sample of Californians}

\section{Comments}

NOTICE: this is the author's version of a work that was accepted for publication in Annals of Epidemiology. Changes resulting from the publishing process, such as peer review, editing, corrections, structural formatting, and other quality control mechanisms may not be reflected in this document. Changes may have been made to this work since it was submitted for publication. A definitive version was subsequently published in Annals of Epidemiology, volume 23, issue 7, in 2013. DOI: 10.1016/j.annepidem.2013.04.012

The Creative Commons license below applies only to this version of the article.

\section{Creative Commons License}

\section{(c) 1 (1) 90}

This work is licensed under a Creative Commons Attribution-Noncommercial-No Derivative Works 4.0 License.

\section{Copyright}

Elsevier

\section{Authors}

Georgiana Bostean, Christian K. Roberts, Catherine M. Crespi, Michael Prelip, Anne Peters, Thomas R. Belin, and William J. McCarthy 


\title{
Cardiovascular Health: Associations with Race-ethnicity, Nativity, and Education in a Diverse, Population-based Sample of Californians
}

\author{
Georgiana Bostean, Ph.D. ${ }^{1}$, Christian K. Roberts, Ph.D. ${ }^{2}$, Catherine M. Crespi ${ }^{3}$, Michael \\ Prelip, DPA, MPH ${ }^{4}$, Anne Peters, MD $^{5}$, Thomas R. Belin, Ph.D. ${ }^{3}$, and William J. McCarthy, \\ Ph.D.6 \\ ${ }^{1}$ Cancer Prevention and Control Research, Fielding School of Public Health, University of \\ California, Los Angeles \\ ${ }^{2}$ Exercise and Metabolic Disease Research Laboratory, Translational Sciences Section, School of \\ Nursing, University of California, Los Angeles \\ ${ }^{3}$ Department of Biostatistics, Fielding School of Public Health, University of California, Los \\ Angeles \\ ${ }^{4}$ Department of Community Health Sciences, Fielding School of Public Health, University of \\ California, Los Angeles \\ ${ }^{5}$ University of Southern California, Keck School of Medicine, Los Angeles \\ ${ }^{6}$ Department of Health Services, Fielding School of Public Health \& Department of Psychology, \\ University of California, Los Angeles
}

\section{Abstract}

Purpose-This study examined how race-ethnicity, nativity, and education interact to influence disparities in cardiovascular (CV) health, a new concept defined by the American Heart Association (AHA). We assessed whether race-ethnicity and nativity disparities in CV health vary by education, and whether the foreign-born differ in CV health from their US-born race-ethnic counterparts with comparable education.

Methods-We used data from the 2009 California Health Interview Survey to determine the prevalence of optimal CV health metrics (based on selected AHA guidelines) among adults ages 25 and over $(n=42,014)$. We examined the interaction between education and ethnicity-nativity, comparing predicted probabilities of each $\mathrm{CV}$ health measure between US-born and foreign-born Whites, Asians, and Latinos.

Results-All groups were at high risk of suboptimal physical activity levels, fruit and vegetable and fast food consumption, and overweight/obesity. Those with higher education were generally better-off, except among Asians. Ethnicity-nativity differences were more pronounced among those with less than a college degree. The foreign-born exhibited both advantages and

(C) 2013 Elsevier Inc. All rights reserved.

Corresponding Author: Georgiana Bostean, Ph.D., UCLA Cancer Prevention and Control Research, A2-125 CHS, mc 690015, 650 Charles Young Drive, Los Angeles, CA 90095-6900, gbostean@ucla.edu; 310-206-8954(voice); 310-206-3566(fax).

Disclosures: None.

Publisher's Disclaimer: This is a PDF file of an unedited manuscript that has been accepted for publication. As a service to our customers we are providing this early version of the manuscript. The manuscript will undergo copyediting, typesetting, and review of the resulting proof before it is published in its final citable form. Please note that during the production process errors may be discovered which could affect the content, and all legal disclaimers that apply to the journal pertain. 
disadvantages in CV health compared to their US-born counterparts that varied by ethnicitynativity.

Conclusions-Education influences ethnicity-nativity disparities in CV health, with most raceethnic and nativity differences occurring among the less educated. Studies of nativity differences in CV health should stratify by education in order to adequately address SES differences.

\section{Keywords}

risk factors; lifestyle; immigrants; health behavior

\section{Introduction}

Cardiovascular (CV) disease is the leading cause of death in the United States, accounting for 1 in 3 deaths [1]. Disparities persist in CV risk factors, morbidity and mortality rates. As a result, the American Heart Association (AHA) has recommended monitoring race-specific trends in "CV health," a new concept defined by a combination of recommended health behaviors and absence of risk factors related to CV outcomes [2]. This study investigates how race-ethnicity, nativity, and education interact to influence differences in CV health.

Race-ethnic and nativity disparities in CV-related health outcomes and behaviors among US adults are well-documented [3-5]. For example, Asians have lower age-adjusted prevalence rates of heart disease, hypertension, and stroke than Whites and Latinos [6]. Latinos have lower age-adjusted prevalence rates of heart disease, coronary heart disease, and hypertension [1], and lower coronary heart disease mortality [7] compared to non-Latino Whites, but higher rates of diabetes [8] and obesity [9]. Foreign-born individuals, although not uniformly advantaged [for review, see 10], generally have lower rates than the US-born of CV mortality [11], heart disease [3], and hypertension [3, 11]. The foreign-born often engage in healthier behaviors than the US-born, such as avoiding smoking [12, 13]. Thus, the portrait of population CV health is complex.

It remains unclear to what extent these disparities are due to socioeconomic status (SES), particularly education [5], because most studies of race-ethnic and nativity disparities in CV risk factors and outcomes inadequately account for group differences in SES. Education is a major contributor to disparities in CV risk factors and outcomes [14], and perhaps the best SES predictor of good cardiovascular health [15]. Long-observed differences in smoking prevalence between Blacks and Whites turned out to be largely explained by differences in educational attainment [16]. The same may be true for the role of education in explaining ethnic and nativity differences in CV health. Education is especially important in studies of ethnic-immigrant health because it is strongly associated with race-ethnicity and nativity [5], time living in the US, and English language proficiency [17], and because immigrants comprise both the most educated and least educated groups in the United States [18].

Yet most studies of differences in CV-related outcomes, especially those that examine nativity, do not fully account for educational differences between race-ethnic and nativity groups because they merely statistically control for education [19]. Among the notable exceptions is a study which found that socioeconomic position was related to arterial calcification (a measure of $\mathrm{CV}$ risk) differentially by immigrant generation and acculturation among Mexicans in the Multi-Ethnic Study of Atherosclerosis study [20]. Another study [21] found that disparities in cardiovascular risk between Whites, Blacks and foreign-born and US-born Mexicans, are largely explained by income and education. Nevertheless, few studies have examined CV health by race-ethnicity, nativity, and education concurrently, thus more careful consideration of how these factors combine to influence CV health disparities is needed. If education explains much of the ethnic and nativity differences in $\mathrm{CV}$ 
health, and differences are concentrated among the lower education group, it may suggest the importance of investing in education for at-risk groups as a practical public health strategy.

This study examined selected CV health behaviors and health status measures [2] to address the following questions: 1 . Do race-ethnic and nativity differences in $\mathrm{CV}$ health vary by education? 2. Do the foreign-born differ in CV health from their US-born race-ethnic counterparts of comparable education? We contribute to the literature by: (a) examining predicted probabilities of $\mathrm{CV}$ health metrics; (b) investigating disparities within and between education groups; (c) assessing nativity differences by race-ethnicity and education; (d) examining the independent effect of education while controlling for other SES measures including housing tenure, income, and employment. We examined a large, ethnically diverse sample of California adults from the most recent statewide health survey, the 2009 California Health Interview Survey (CHIS). California has the largest populations of Latinos, Asians and non-Hispanic Whites of any state, and nearly 1 in 3 residents is foreignborn [22]. We hypothesized that ethnicity-nativity differences in CV health vary by education, with fewer disparities among the higher education group.

\section{Methods}

\section{Data and Sample}

Data were from the 2009 CHIS [23], a population-based cross-sectional telephone survey of California's population. The multi-stage sampling design utilized random-digit-dial (RDD) of landline and cellular telephones to recruit respondents. Data were collected using computer-assisted telephone interviewing. The 2009 overall response rate $(36.1 \%)$ is comparable to other California surveys [24] and national RDD surveys [25]. In 2007, CHIS conducted an assessment of nonresponse bias and found few significant differences between respondents and non-respondents [26]. The CHIS sample is considered to be representative of the California population when sampling weights are used to account for the sampling design and to adjust for differential non-response. The data underwent a rigorous imputation process to address missing data prior to public release, therefore there are no missing values included in the data analyzed here [27]. We limited analyses to adults ages 25 and over, of White, Latino or Asian ethnicity. Other race-ethnic groups were excluded because of small sample sizes, especially of foreign-born. The final analytic sample size was 42,014. All measures were self-reported.

\section{Dependent Variables}

We used the AHA conceptualization of "ideal cardiovascular health" [2] to select and code five health behaviors and four health status measures. Variables were coded as multicategorical for initial analyses and dichotomous for logistic regression analyses, with the outcome of compliance vs. noncompliance with the AHA recommendation.

Health behaviors-Smoking status was defined as never smoked (has not smoked 100 or more cigarettes in lifetime; optimal) or current or former smoker (not optimal). Physical activity was assessed as the number of minutes of leisure time moderate and vigorous physical activity in the week before the interview. We multiplied vigorous minutes by two to obtain moderate-equivalent minutes [28], then summed the moderate and moderateequivalent minutes to obtain total minutes of moderate-equivalent activity, categorized as: sedentary (0 minutes/week); suboptimal (1-149 minutes/week of moderate-equivalent minutes); and optimal ( $\geq 150$ minutes per week of moderate-equivalent minutes). The dichotomous measure was optimal/not optimal. Sugar-sweetened beverage consumption was assessed in CHIS as number of times in the past week the respondent reported 
consuming soda, sugar-sweetened coffee or tea, or sugar-added juice, excluding sugar-free or diet drinks. We assumed each "time" corresponded to an 8 ounce serving, which probably underestimated consumption because the beverages included coffee, tea and juice, which are typically consumed in $8 \mathrm{oz}$. servings, in contrast to sodas, which are typically consumed in 12 to 20 oz. servings. In initial analyses, we examined the categories < 16 oz., $16-36$ oz., > 36 oz. The dichotomous measure was optimal ( $\leq 36$ oz./week)/not optimal (> 36 oz./week). Fast food consumption was coded dichotomously in regression analyses as ate no fast food in past week (optimal)/ate fast food at least once in the last week (not optimal). Although fast food is not explicitly included in the AHA recommendations, previous studies have found that consuming fast food more than twice per week is associated certain health conditions [29]. Sensitivity analyses explored various cut-points, but results remained largely the same when controlling for sociodemographic factors. Fruit and vegetable consumption was defined as $\geq 5$ servings/day (optimal) or $<5$ servings (not optimal). The AHA recommendation is nine servings per day; however we chose to use five for greater comparability with previous research [30]. Initial analyses included categories: $<1,1-2.9$, $3-4.9$, and $\geq 5$ servings/day.

Health status measures-Obesity status was estimated using body mass index (BMI), calculated from self-reported height and weight, and coded as not overweight or obese $(<25$ $\left.\mathrm{kg} / \mathrm{m}^{2}\right)$, overweight $\left(25-29.99 \mathrm{~kg} / \mathrm{m}^{2}\right)$ or obese $\left(\geq 30 \mathrm{~kg} / \mathrm{m}^{2}\right)$. The dichotomous variable was coded as not obese/overweight (optimal), obese or overweight (not optimal). For high blood pressure, heart disease, and diabetes, respectively, respondents were asked if they were ever told by a doctor that they had the condition. Three indicators were coded dichotomously (optimal $=$ has not been told has condition; not optimal $=$ has been told has condition).

\section{Independent Variables}

Ethnicity-nativity-We combined respondents' race-ethnicity and nativity (based on the question, "Were you born in the United States?") into a measure of "ethnicity-nativity": native-born non-Latino Whites ("NB Whites"); foreign-born non-Latino Whites ("FB Whites"); native- born Latinos ("NB Latinos"); foreign-born Latinos ("FB Latinos"); nativeborn Asians ("NB Asians"); and foreign-born Asians ("FB Asians"). The Latino group is predominantly Mexican, with Salvadorans, Guatemalans and other Latinos; the Asian sample consists of Vietnamese (largest Asian subgroup in unweighted data), Chinese, Koreans, Filipino and other Asians. The terms "native-born" and "US-born" are used interchangeably to refer to those who were born in the United States.

Educational attainment-The socioeconomic measure of interest was educational attainment $(1=$ college degree or higher; $0=$ less than college degree $)$. Much of the previous research shows that the largest health differences are between the college educated and those with less education. We conducted analyses using several different cut-offs (less than high school versus high school or more; up to high school versus some college or more; and less than college versus college or more). We were unable to use high school as a cut-off because of the very small number of U.S.-born Asians with less than a high school education, and patterns were largely the same when using some college as the cut-off. Thus, we chose to use the college cutoff with ages 25 and over in our final analyses in order to maintain adequate cell sizes for all race-ethnic and nativity groups by education.

Covariates-To examine the net effect of education, additional socioeconomic status indicators were included: family income below federal poverty line (reference: 100\%+ of FPL); unemployment (reference: currently employed); does not own home (reference: owns home). Health care access and utilization indicators were: no health insurance coverage any 
time in past 12 months (reference: continuous coverage in past year); rural residence (reference $=$ not rural); no doctor visit in the past 12 months (reference: doctor visit in past 12 months); no usual source of care (reference: has usual source of care). Sociodemographic indicators included: age (continuous), sex (reference: male), and not married (reference: married). Based on the immigrant health literature, we also included the following variables to control for their potential confounding effect with nativity: limited English proficiency (reference: speaks English well or very well); not a US citizen (reference: US citizen); percent of life lived in the US (reference group: $0-40 \%, 41-80 \%, 81 \%+$ ).

\section{Analyses}

Analyses were conducted in Stata version 12 [31], using Stata's svy suite of survey data analysis commands. We first examined sociodemographic characteristics by education and ethnicity-nativity, weighted to be representative at the state level (Table 1). Chi-square tests of independence examined ethnicity-nativity differences in each outcome, within education groups. Next, we examined the prevalence of health behaviors and health status by ethnicitynativity and education (Table 2). We age-standardized the prevalence rates of heart disease, high blood pressure, and diabetes, using 2010 U.S. Census data for the California population. To examine whether ethnicity-nativity and education interact to influence $\mathrm{CV}$ health while controlling for other factors, we fit logistic regressions for each optimal CV health measure; these models included main effects of education and ethnicity-nativity and terms for their interaction, and controlled for the aforementioned covariates, as well as an interaction between age and percent of life in the U.S. to control for differences by age at immigration (Supplemental Table). Additionally, the models predicting health behaviors controlled for health conditions (diabetes, heart disease, hypertension, and overweight/ obesity). For each outcome, Wald tests examined the statistical significance of the overall interaction (F-statistics are reported). We adjusted for multiple comparisons using the Bonferroni method. Predicted probabilities for each outcome were calculated from the fitted logistic regression equation as follows:

$$
\widehat{p}=\exp \left(\widehat{\alpha}+\widehat{\beta}_{1} x_{1}+\cdots+\widehat{\beta}_{k} x_{k}\right) /\left[1+\exp \left(\widehat{\alpha}+\widehat{\beta}_{1} x_{1}+\cdots+\widehat{\beta}_{k} x_{k}\right)\right] .
$$

Ethnicity-nativity and education were explicitly fixed, and all other covariates were set equal to their means over the entire sample. This type of predicted probability is referred to as a predictive margin or marginal effect at the means [32] and provides the estimated probability of the outcome for an individual with the specified value of the covariates. We plotted the predicted probabilities of the ethnicity-nativity groups by education for each measure of CV health (Figure 1). Z-tests were used to assess nativity differences in predicted probabilities within race-ethnic and education groups, using the Simes procedure to control the false discovery rate (Table 3) [33].

\section{Results}

Table 1 compares the sociodemographic characteristics of California adults stratified by education level. Not surprisingly, those with less than a college degree had worse socioeconomic profiles overall. Race-ethnic and nativity differences were generally smaller among the higher education group. For example, among Latinos of lower education, 41.6\% of the FB and $16.5 \%$ of the NB were in poverty; by contrast, only $16.2 \%$ of higher-education FB Latinos and $4.8 \%$ of NB Latinos were in poverty.

There were also differences in the prevalence of CV health factors by education and ethnicity-nativity (Table 2). Those with a college degree generally had higher rates of never smoking and optimal physical activity but worse patterns of fast food and fruit and vegetable 
consumption compared to their lower education counterparts. Moreover, nativity differences were smaller among the higher education group in many cases, especially among Latinos and Asians. For example, among Asians with a lower education, $44.6 \%$ of the NB and $70.4 \%$ of the FB were never smokers, compared to $84.4 \%$ and $82.1 \%$ of their higher education counterparts, respectively. Similarly, among Latinos, $58.4 \%$ of the NB and $69.7 \%$ of the FB with a lower education were never smokers, compared to $75.8 \%$ and $72.1 \%$ of their higher education counterparts.

\section{Do race-ethnic and nativity differences in CV health vary by education?}

We examined whether education and ethnicity-nativity interact to influence differences in $\mathrm{CV}$ health factors, controlling for sociodemographic differences between these groups (regression results presented in Supplemental Table). The overall interaction was significant for smoking, fast food consumption, fruit and vegetable consumption, BMI, and high blood pressure, indicating that the association between optimal CV health and ethnicity-nativity varied by educational attainment.

To aid in the interpretation of the interaction, Figure 1 plots predicted probabilities of meeting the modified AHA recommendations for each CV health measure, holding covariates constant at their means. Among most groups, the probability of optimal CV health (for any particular outcome) was higher among the college-educated. However, this was less often the case among Asians. College-educated Asians had worse fast food consumption compared to their less educated counterparts, regardless of nativity. In terms of BMI and high blood pressure, FB Asians with a college education had worse outcomes than their lower education counterparts.

In addition, ethnicity-nativity disparities were generally smaller among the college-educated, especially for smoking, diabetes, high blood pressure and BMI. For sugary beverage consumption, the difference between education groups was much greater among FB Latinos than other groups. In other words, especially for Latinos, having a college education was associated with a more favorable CV health outcome (i.e., lower consumption of sugary beverages).

While there were important disparities in CV health, nearly all groups had suboptimal behaviors in terms of physical activity, fast food consumption, fruit and vegetable consumption, and BMI. The predicted probabilities of having optimal outcomes (i.e., meeting the recommendations) for these $\mathrm{CV}$ health measures were low for all groups: between 35-45\% for physical activity, 25-50\% for fast food consumption, 25-50\% for BMI (excluding Asians), and 3-10\% for fruit and vegetable consumption.

\section{Do the foreign-born differ in CV health from their US-born race-ethnic counterparts of comparable education?}

We tested for nativity differences in the predicted probabilities of each outcome within each race-ethnic and education group (Table 3 ). Significant nativity differences were mostly limited to the less educated group, with the FB generally having advantages over their NB counterparts. Among the less educated, FB Asians and Latinos had significantly higher predicted probabilities of never smoking than the NB. In sum, when comparing within raceethnic and education groups, there are few nativity differences, but where there are differences, those are small and generally confined to the lower education group.

\section{Discussion}

This study examined disparities in CV health behaviors and health status measures by ethnicity-nativity and education. We asked whether disparities varied by education, and 
whether the foreign-born differed in CV health from their US-born counterparts of comparable education. Our major findings indicated that: (1) ethnicity-nativity interact with education to influence disparities in some $\mathrm{CV}$-related outcomes, with more and greater disparities among those with less education; and, (2) the foreign-born have both advantages and disadvantages in CV health compared to their counterparts, and these vary by racenativity. Also of note is that while those with higher education were generally better-off, all groups, regardless of ethnicity-nativity and education, had large proportions of persons who had suboptimal outcomes in terms of physical activity, fruit and vegetable consumption, fast food consumption, and BMI. The study suggests that studies of nativity differences in CV health should stratify by education in order to adequately address SES differences.

The fact that nativity differences are greater among the less educated group suggests that educational attainment is a major moderating factor [34] and social determinant of raceethnic and nativity disparities in cardiovascular health behaviors and outcomes. Education was a significant predictor of CV health behaviors and health status measures, even controlling for housing tenure, employment status, family income, and other SES measures. Other studies have found similarly strong evidence of the importance of education and social-structural factors in determining health behaviors and outcomes. Fuentes-Afflick and Hessol [35] examined the association between acculturation and overweight among Latina women, finding that education was inversely related to overweight, while acculturation measures were largely not associated with overweight or obesity, with the exception of time lived in the US. Education can affect health in multiple ways-for example, by: directly impacting knowledge, literacy, and behaviors related to health; affecting work, including working environment, income, access to health insurance and other work-related resources; or by impacting individuals' sense of control, social standing or social support [36]. Thus, insofar as education reflects access to important health-related resources-personal, social, or structural—it is a major determinant of individual health, and population health differences. While our data cannot speak to the causal nature of the association between education and health risks, these findings may help to identify intervention priorities for particular population groups.

Beyond education, race and nativity also remained important in patterning CV health. For example, the foreign-born are less likely than the US-born to meet physical activity recommendations, a finding that is supported by other research [19, 37]. Comparing persons at similar levels of education reduced ethnicity-nativity differences, but did not eliminate them. Moreover, we controlled for several measures often used as proxies for acculturation (English language proficiency, US citizenship) yet nativity differences remained, even within race-ethnic and education groups. Thus, nativity differences are not fully explained by these factors. Other social-structural issues may be important in shaping these differences. While this study has focused on individual health behaviors, these behaviors are often determined by environmental influences such as, food quality, food procurement policy, and marketing $[38,39]$. Future research should examine the interplay between individuals' behaviors and the political economy in order to effectively address the upstream influences on these individual behavioral risks.

Some issues could not be addressed here. Due to the cross-sectional nature of the CHIS data, we were unable to assess causality in the education-health behavior association. Additional limitations of the CHIS survey are that health behaviors are self-reported, and some of the AHA-defined CV health components are not included in the survey (e.g., food preservation, processing and preparation). We were unable to include Black groups because of small numbers of foreign-born Blacks in the sample; therefore, these results are not generalizable to this important minority group. There are also large variations within the broad categories of ethnicity examined here [40] that could not be addressed. Future studies can build upon 
this work by: using a longitudinal design to examine how health behaviors change as individuals' educational attainment increases, including additional race groups and more nuanced race-ethnicity subgroups, and examining respondents in other states. Despite its limitations, this study provides important findings concerning race and nativity disparities in $\mathrm{CV}$ health-related behaviors and measures, and how they varied by education.

The AHA has argued that, "for effective disease prevention, population-level strategies are essential to shift the entire distribution of risk" [2]. This study suggests that to reduce CV risk in diverse and underserved populations, both behavioral interventions and policy approaches to achieve social structural changes are needed. Part of the public health approach to achieving this may involve increasing access to education-an important source of health-related knowledge, literacy, and resources. Yet even among the most educated, there are still disparities in health behaviors that behavioral interventions may effectively reduce. In sum, both social structural changes such as increasing access to education, and behavioral interventions should be utilized to reduce disparities in morbidity and mortality from CVD and other chronic diseases.

\section{Supplementary Material}

Refer to Web version on PubMed Central for supplementary material.

\section{Acknowledgments}

Funding Sources

The authors were supported by National Institutes of Health grants P50HL105188 (W.J.M., M.P., A.P., T.R.B., and C.K.R.), R01DK090406 (C.K.R.), R25CA087949 (G.B.) and U54 RR033176 (C.M.C.).

The authors would like to thank the anonymous reviewers and Dr. Alexander Ortega for their comments on earlier versions of this manuscript.

\section{Abbreviations}

CV Cardiovascular

AHA American Heart Association

CHIS California Health Interview Survey

RDD random-digit-dial

NB Native-born

FB Foreign-born

BMI Body Mass Index

\section{References}

1. Roger VL, Go AS, Lloyd-Jones DM, Benjamin EJ, Berry JD, Borden WB, et al. Heart Disease and Stroke Statistics 2012 Update. Circulation. 2012 Jan 3; 125(1):e2-e220. [PubMed: 22179539]

2. Lloyd-Jones DM, Hong Y, Labarthe D, Mozaffarian D, Appel LJ, Van Horn L, et al. Defining and Setting National Goals for Cardiovascular Health Promotion and Disease Reduction. Circulation. 2010; 121(4):586-613. [PubMed: 20089546]

3. Jasso, G.; Massey, DS.; Rosenzweig, MR.; Smith, JP. Immigrant Health: Selectivity and Acculturation. In: Anderson, NB.; Bulatao, RA.; Cohen, B., editors. Critical Perspectives on Racial and Ethnic Differences in Health in Late Life. Washington, D.C: The National Academies Press; 2004. p. 227-66. 
4. Williams DR, Sternthal M. Understanding Racial-ethnic Disparities in Health. J Health Soc Behav. 2010; 51(1 suppl):S15-S27. [PubMed: 20943580]

5. Williams DR. The Health of U.S. Racial and Ethnic Populations. The Journals of Gerontology Series B: Psychological Sciences and Social Sciences. 2005 Oct 1; 60(Special Issue 2):S53-S62.

6. Barnes PM, Adams PF, Powell-Griner E. Health characteristics of the Asian adult population: United States, 2004-2006. Adv Data. 2008 Jan 22.(394):1-22. [PubMed: 18271366]

7. Palaniappan L, Wang Y, Fortmann SP. Coronary heart disease mortality for six ethnic groups in California, 1990-2000. Ann Epidemiol. 2004; 14(7):499-506. [PubMed: 15310526]

8. Harris MI, Flegal KM, Cowie CC, Eberhardt MS, Goldstein DE, Little RR, et al. Prevalence of diabetes, impaired fasting glucose, and impaired glucose tolerance in U.S. adults. The Third National Health and Nutrition Examination Survey, 1988-1994. Diabetes Care. 1998 Apr 1; 21(4): 518-24. [PubMed: 9571335]

9. Singh G, Kogan M, Yu S. Disparities in Obesity and Overweight Prevalence Among US Immigrant Children and Adolescents by Generational Status. J Community Health. 2009; 34(4):271-81. [PubMed: 19333745]

10. Argeseanu Cunningham S, Ruben JD, Venkat Narayan KM. Health of foreign-born people in the United States: A review. Health \& Place. 2008; 14(4):623-35. [PubMed: 18242116]

11. Singh G, Siahpush M. All-cause and cause-specific mortality of immigrants and native born in the United States. Am J Public Health 2001. 2012/08/07; 91(3):392-9.

12. Singh, GK.; Siahpush, M. Ethnic-Immigrant Differentials in Health Behaviors, Morbidity, and Cause- Specific Mortality in the United States: An Analysis of Two National Data Bases. Wayne State University Press; 2002.

13. Blue L, Fenelon A. Explaining low mortality among US immigrants relative to native-born Americans: the role of smoking. Int J Epidemiol. 2011; 40(3):786-93. [PubMed: 21324939]

14. Diez Roux AV, Detrano R, Jackson S, Jacobs DR, Schreiner PJ, Shea S, et al. Acculturation and Socioeconomic Position as Predictors of Coronary Calcification in a Multiethnic Sample. Circulation. 2005 Sep 13; 112(11):1557-65. [PubMed: 16144996]

15. Winkleby MA, Jatulis DE, Frank E, Fortmann SP. Socioeconomic status and health: how education, income, and occupation contribute to risk factors for cardiovascular disease. Am J Public Health 1992. 2012/08/06; 82(6):816-20.

16. Kiefe CI, Williams OD, Lewis CE, Allison JJ, Sekar P, Wagenknecht LE. Ten-year changes in smoking among young adults: are racial differences explained by socioeconomic factors in the CARDIA study? Am J Public Health. 2001; 91(2):213-8. [PubMed: 11211629]

17. Guinn R, Vincent V, Lin W, Villas P. Acculturation Tendencies in a Border Latino Population. Hispanic Journal of Behavioral Sciences. 2011 May 1; 33(2):170-83.

18. Motel, S.; Patten, E. Statistical Portrait of the Foreign-Born Population in the United States, 2011. Washington, D.C: Pew Hispanic Center; 2013.

19. Abraío-Lanza AF, Chao MT, Flóez KR. Do Healthy Behaviors Decline with Greater Acculturation?: Implications for the Latino Mortality Paradox. Soc Sci Med. 2005; 61(6):1243-55. [PubMed: 15970234]

20. Gallo LC, de los Monteros KE, Allison M, Roux AD, Polak JF, Watson KE, et al. Do Socioeconomic Gradients in Subclinical Atherosclerosis Vary According to Acculturation Level? Analyses of Mexican- Americans in the Multi-Ethnic Study of Atherosclerosis. Psychosom Med. 2009 Sep; 71(7):756-62. [PubMed: 19661194]

21. Karlamangla AS, Merkin SS, Crimmins EM, Seeman TE. Socioeconomic and Ethnic Disparities in Cardiovascular Risk In the United States, 2001-2006. Ann Epidemiol. 2010; 20(8):617-28. [PubMed: 20609342]

22. U.S. Census Bureau. Bureau USC. American Community Survey 5-year estimates. 2011. Table S0501: Selected Characteristics of the native and foreign-born populations.

23. UCLA Center for Health Policy Research. Report 1 - Sample Design. Los Angeles, CA: UCLA; 2011 Nov.

24. California Health Interview Survey. Report 4 - Response Rates. Los Angeles, CA: UCLA; 2011. 
25. National Cancer Institute. Health Information National Trends Survey 2003: Final Report 2003. Oct. 2003 updated 2003; cited 8/9/2012Available from: http://hints.cancer.gov/docs/ HINTS_2003_final_report.pdf

26. UCLA Center for Health Policy Research. CHIS Data Quality: CHIS 2007 Nonresponse Analysis. Los Angeles: 2007. [updated 2007; cited 2013 3/3]; Available from: http://healthpolicy.ucla.edu/ chis/design/Pages/data-quality3.aspx

27. UCLA Center for Health Policy Research. CHIS 2009 Methodology Report Series: Report 3 Data Processing Procedures. Los Angeles: UCLA; 2011.

28. Shay CM, Ning H, Allen NB, Carnethon MR, Chiuve SE, Greenlund KJ, et al. Status of Cardiovascular Health in US Adults/Clinical Perspective. Circulation. 2012; 125(1):45-56. [PubMed: 22095826]

29. Pereira MA, Kartashov AI, Ebbeling CB, Van Horn L, Slattery ML, Jacobs DR Jr, et al. Fast-food habits, weight gain, and insulin resistance (the CARDIA study): 15-year prospective analysis. The Lancet. 2005; 365(9453):36-42.

30. Erinosho TO, Moser RP. Awareness of the Fruits and Veggies-More Matters campaign, knowledge of the fruit and vegetable recommendation, and fruit and vegetable intake of adults in the 2007

Food Attitudes and Behaviors (FAB) Survey. Appetite. 2012; 59(1):155-60. [PubMed: 22524998]

31. StataCorp. Stata Statistical Software: Release 12. College Station, TX: StataCorp LP; 2011.

32. Cameron, A.; Trivedi, P. Microeconometrics: Methods and Applications. Cambridge, UK: Cambridge University Press; 2005.

33. Benjamini Y, Yekutieli D. The Control of the False Discovery Rate in Multiple Testing under Dependency. The Annals of Statistics. 2001; 29(4):1165-88.

34. Wickrama KAS, O'Neal CW, et al. Early Community Contexts, Race/Ethnicity and Young Adult CVD Risk Factors: The Protective Role of Education. J Community Health. 2012; 37(4):781-90. [PubMed: 22101680]

35. Fuentes-Afflick E, Hessol NA. Acculturation and Body Mass among Latina Women. Journal of Women's Health. 2008; 17(1):67-73.

36. Braveman P, Egerter S, Williams DR. The Social Determinants of Health: Coming of Age. Annu Rev Public Health. 2011; 32(1):381-98. [PubMed: 21091195]

37. Crespo CJ, Smit E, Carter-Pokras O, Andersen R. Acculturation and Leisure-Time Physical Inactivity in Mexican American Adults: Results From NHANES III, 1988-1994. Am J Public Health. 2001; 91(8):1254-7. [PubMed: 11499114]

38. Nestle, M. Food Politics: How the food industry influences nutrition and health. Berkeley, CA: University of California Press; 2007.

39. Hill JO, Wyatt HR, Reed GW, Peters JC. Obesity and the Environment: Where Do We Go from Here? Science. 2003; 299(5608):853-5. [PubMed: 12574618]

40. Palaniappan LP, Araneta MRG, Assimes TL, Barrett-Connor EL, Carnethon MR, Criqui MH, et al. Call to Action: Cardiovascular Disease in Asian Americans. Circulation. Sep 21; 2010 122(12): 1242-52. [PubMed: 20733105] 

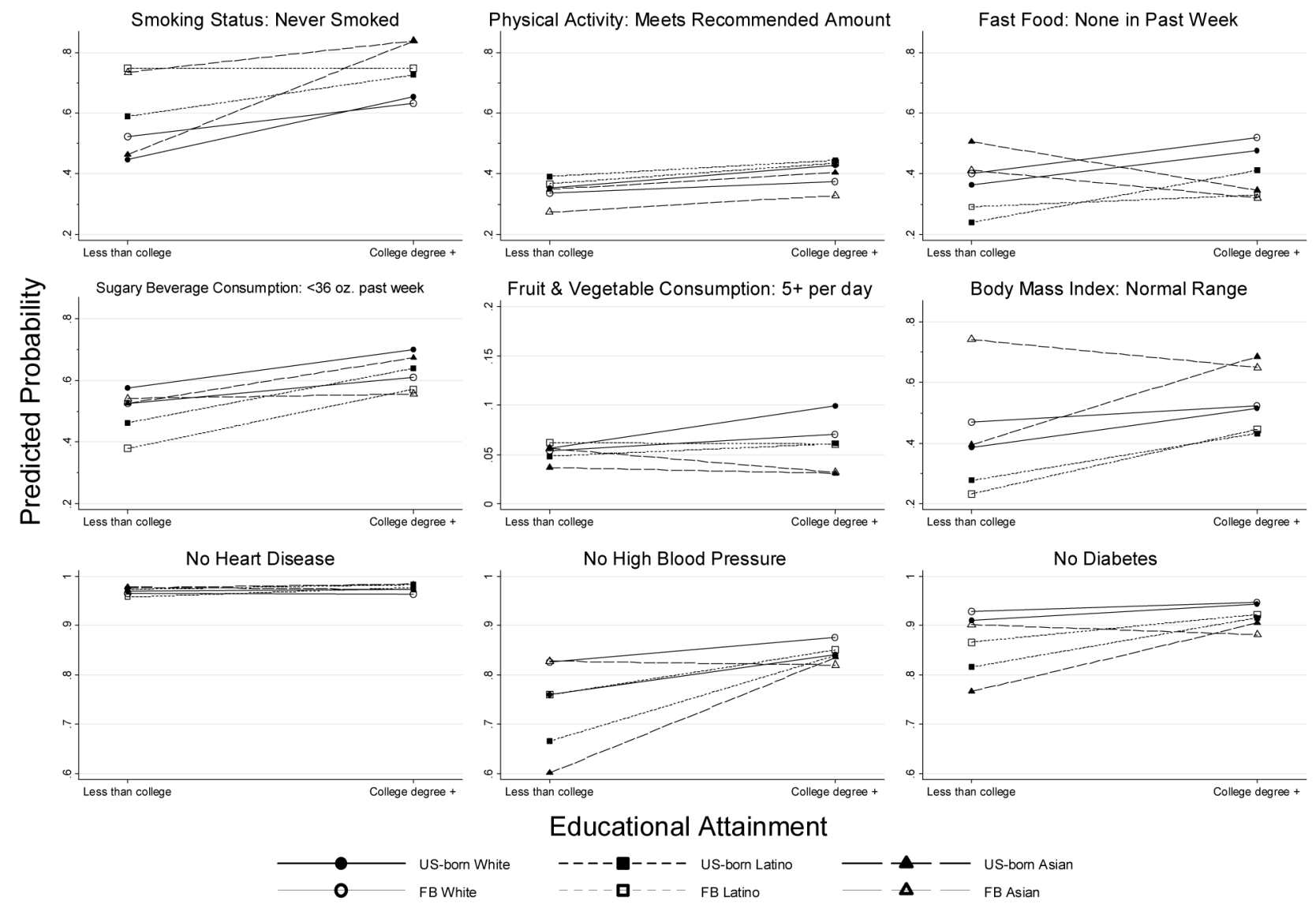

Educational Attainment
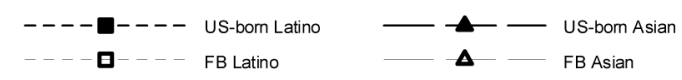

Figure 1.

Conditional Predicted Probabilities of CV Health Components by Ethnicity-Nativity and Education

Notes: Calculated using California Health Interview Survey, 2009. Probabilities range from $0-1$. Predicted probabilities calculated holding covariates constant at their mean values. Covariates include: age, sex, marital status, poverty status, employment status, housing tenure, health insurance status, rural residence, doctor visit past year, usual source of health care, limited English proficiency, U.S. citizenship, percent of life in U.S., and interaction between age and percent of life in U.S. Models predicting health behaviors additionally control for health status. Test of overall interaction between education and ethnicity-nativity significant at the .05 alpha level (Bonferroni-adjusted) for fast food, BMI, high blood pressure, and diabetes. See Supplemental Table for regression results. 
$\mid \begin{gathered}0 \\ \frac{0.0}{2} \\ 7 \\ 7\end{gathered}$

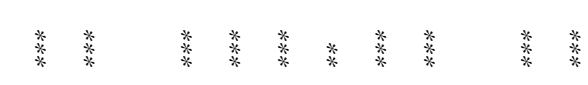




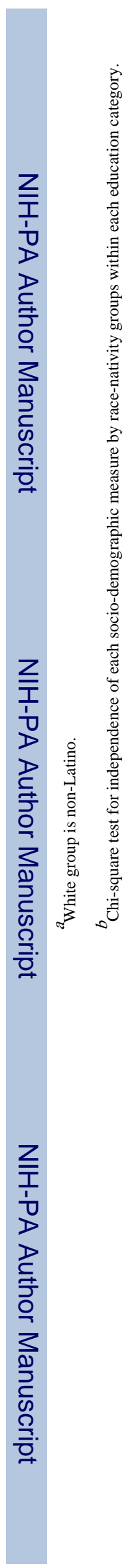

Bostean et al.

Page 13$$
\text { . }
$$

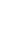

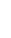

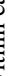

$$
\text { 可 }
$$


政

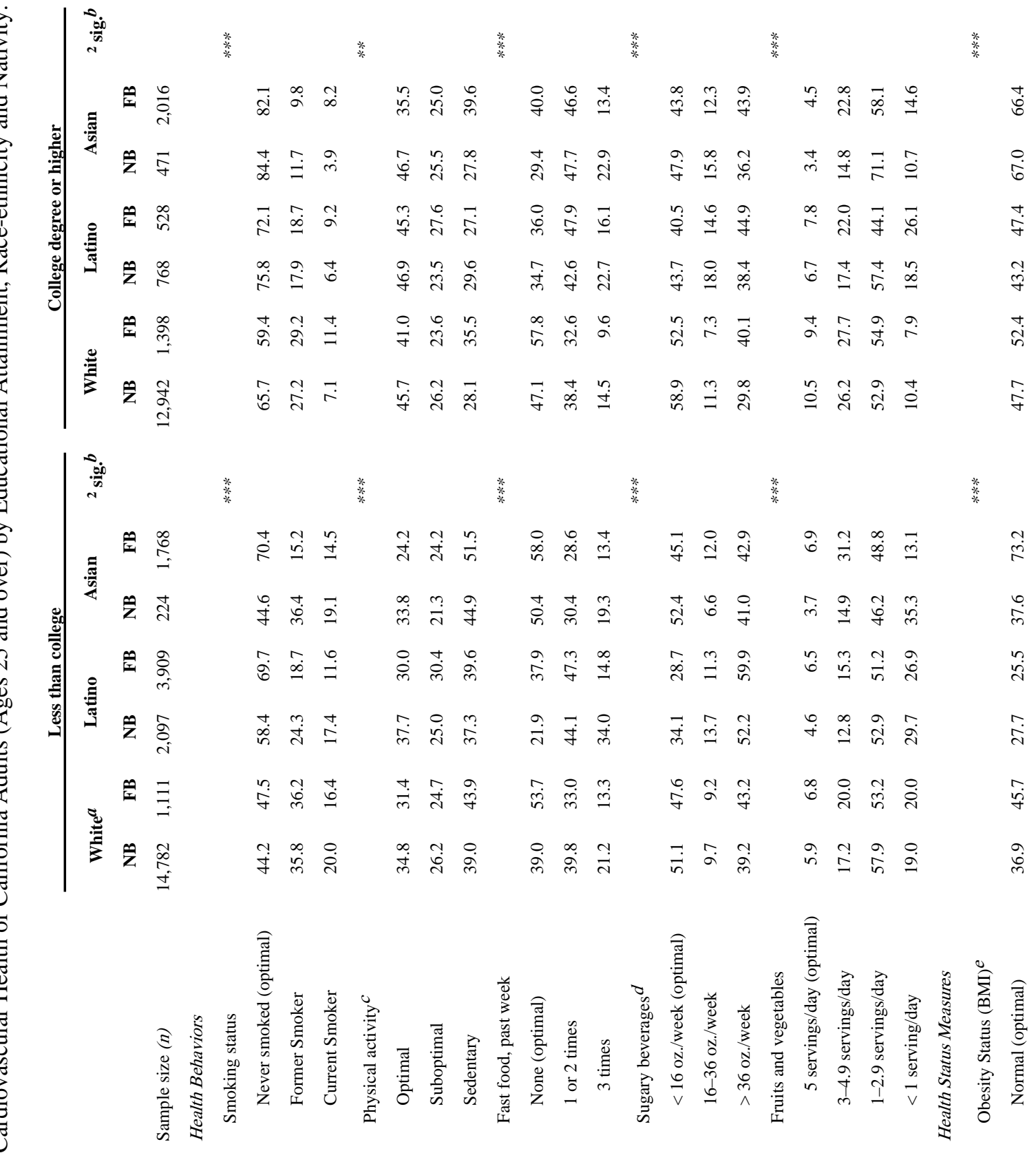




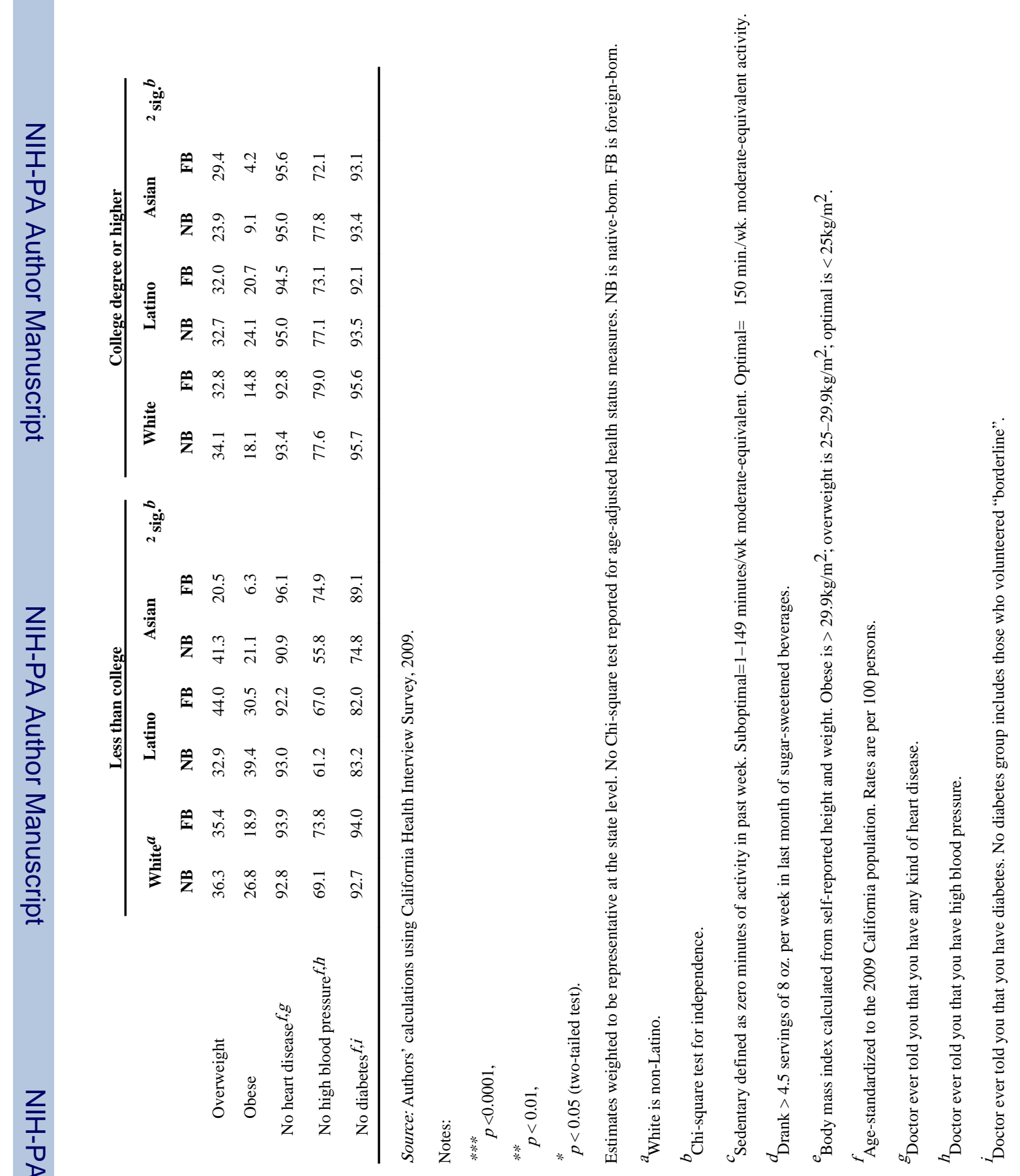




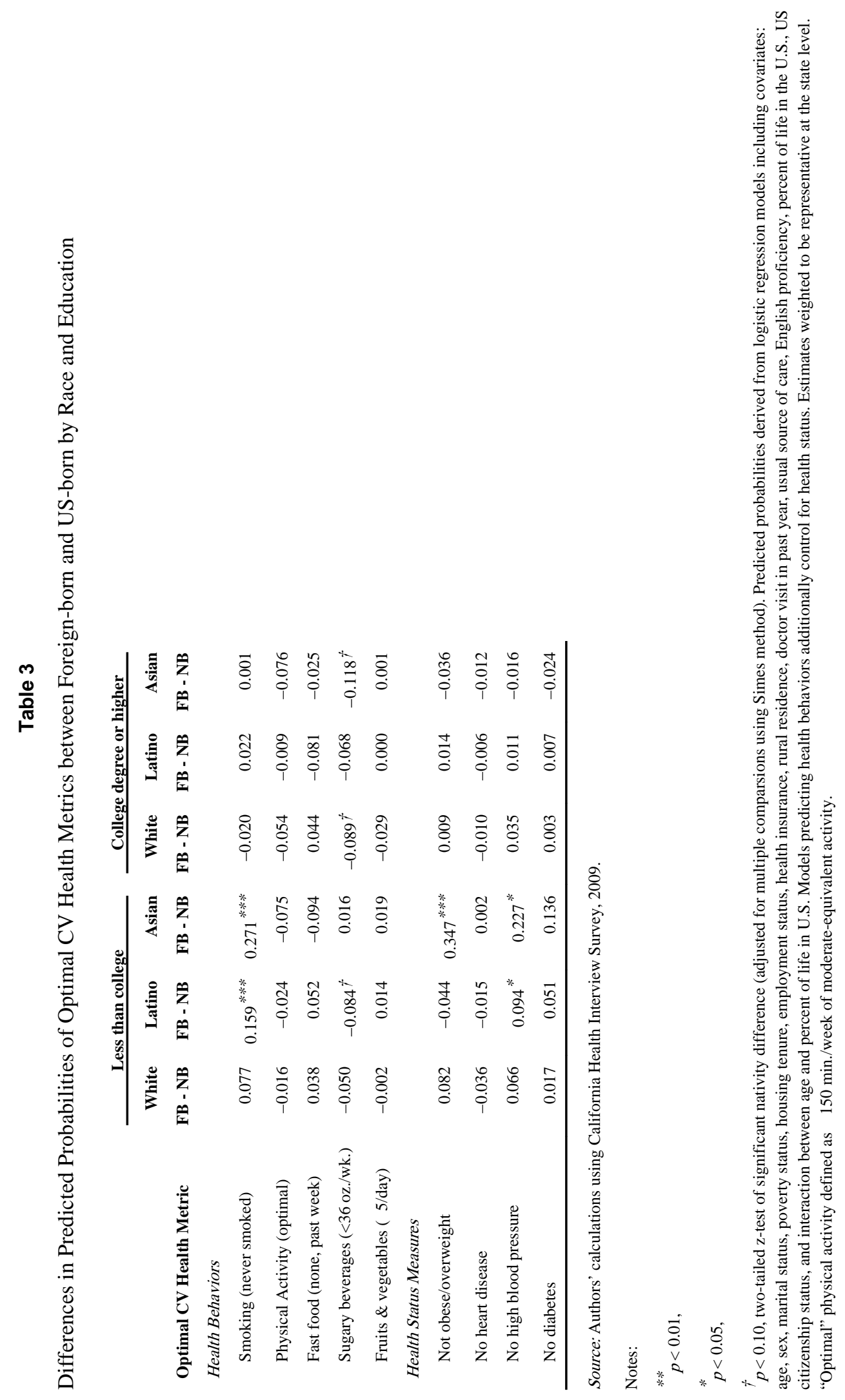

